\title{
Positive Emotion Differentiation: A Functional Approach
}

\author{
Michelle N. Shiota*, Samantha L. Neufeld, Alexander F. Danvers, \\ Elizabeth A. Osborne, Oliver Sng and Claire I. Yee \\ Arizona State University
}

\section{Abstract}

While positive emotion can be conceptualized broadly as a response to the potential for reward, the environment offers different kinds of rewards, and these are best approached in somewhat different ways. A functional approach to positive emotion differentiation distinguishes among several different types of rewards with strong implications for adaptive fitness and posits the existence of "discrete" positive emotions that promote an adaptive response to each reward. A taxonomy of eight positive emotions, dubbed the "PANACEAS" taxonomy based on an acronym of the first letter of each of the eight constructs, is presented as an example of this approach. Positive emotion constructs defined through functional analyses are useful for guiding empirical research, especially for identifying prototypical eliciting stimuli, and generating hypotheses about the implications of different positive emotions for a variety of outcomes. Research findings are reviewed that support the importance of positive emotion differentiation in understanding the effects of positive emotions on cognition, physiology, and behavior. Advantages of the functional approach are discussed, as well as implications of the approach for evaluating major theories of the structure of emotion.

\section{Positive Emotion Differentiation: A Functional Approach}

Imagine that you are in each the following situations: waiting eagerly for a cool drink you just ordered on a hot afternoon; stretching out on your couch after a long day and a satisfying dinner; holding your new baby niece or nephew in your arms; making eye contact with a sexy person you just met at a party; having a loved one care for and comfort you when you're sick; laughing at a joke told by a colleague; and gazing at the view from a high ridge on a mountain. Each of these situations is pleasant. Each offers potential for reward. Yet the nature of the reward varies considerably from situation to situation, and you take advantage of that reward by somewhat different means. While there is undoubtedly overlap in the emotions felt in each of these situations, there are important differences as well.

For the most part, theories of positive emotion have not emphasized the possibility that different positive emotions might have qualitatively distinct implications for cognition, physiological responding, motivation, and behavior, or offered a strong basis for hypotheses about differential effects. A functional approach to positive emotion differentiation helps to address this gap. Analyses of the adaptive functions of "discrete" negative emotion states have long been used to guide research on emotional responding (e.g., Lazarus, 1991), producing a rich body of empirical work. In this paper, we discuss the advantages of using functional analysis to define discrete positive emotion constructs as well; present a taxonomy of eight positive emotions, labeled with the acronym "PANACEAS", that serves as an example of the functional approach; and offer several examples of research guided by the PANACEAS model and similar functional analyses. 


\section{Defining the Functional Approach}

Positive emotions are "functional", in the colloquial sense of being useful or having a desirable effect, in many ways. They enhance our sense of well-being, predict positive life outcomes, and may even promote physical health (e.g., Diener, 2000; Harker \& Keltner, 2001; Pressman \& Cohen, 2005; Steptoe, Wardle, \& Marmot, 2005). In the context of emotion research, however, the term "functional" commonly refers to adaptive function. This perspective presumes that emotional responding helped our ancestors survive, reproduce, and/or care for kin in ways that increased the representation of their genes in each succeeding generation's gene pool. While major theories of emotion disagree about the specific adaptive functions emotions serve and the structure of neural systems that produce emotion, all agree that affect/emotion systems are functional in this sense (e.g., Ekman, 1992; Frijda, 1986; Lazarus, 1991; Nesse \& Ellsworth, 2009; Russell, 2003; Scherer, 2009).

Positive emotions as a class likely serve broad adaptive functions. For example, prior research has documented an "undoing" effect in which positive emotions can help people recover from physiological stress responses associated with negative emotion (Fredrickson \& Levenson, 1998; Fredrickson, Mancuso, Branigan, \& Tugade, 2000). They signal that the environment is safe, facilitating reliance on default or temporarily dominant modes of cognition and behavior (e.g., Huntsinger, Sinclair, Dunn, \& Clore, 2010; Russell, 2003). Positive emotions also promote long-term "upward spirals" of emotion and well-being by broadening attention to a wider scope of the environment, and building personal resources that facilitate downstream well-being and resilience (e.g., Fredrickson, 1998; Fredrickson \& Joiner, 2002; Tugade \& Fredrickson, 2004). In contrast, negative emotions as a class signal danger or loss, promote caution, and mobilize the energy needed to escape or fend off a serious threat to fitness (Cacioppo, Berntson, Larsen, Poehlmann, \& Ito, 2000; Forgas, 1995; Nesse, 1990).

For the most part, research on positive emotion has focused on the features of positive emotions as a class. The bulk of existing research on positive emotion can be summarized as finding that "positive affect/mood/emotion does X", where "X" might involve cognition (e.g., Bodenhausen, Kramer, \& Süsser, 1994; Forgas, 2008; Fredrickson \& Branigan, 2005; Isen, Daubman, \& Nowicki, 1987; Johnson \& Fredrickson, 2005; Mackie \& Worth, 1989), physiology (e.g., Fredrickson \& Levenson, 1998), or behavior (e.g., Ekman et al., 1987). This body of work implicitly reflects a long tradition in which the valence of subjective experience is treated as a primary dimension along which emotions can be differentiated, and their effects predicted and explained (e.g., Lazarus, 1991; Russell, 2003).

Other dimensions have also been used to describe emotion "space" and thus to predict the features of different positive emotions. For example, one body of research emphasizes the dimension of approach motivation (e.g., Carver \& White, 1994; Harmon-Jones, 2003). This research has found that approach motivation is not synonymous with positive valence, as anger shows strong signs of approach motivation (e.g., Carver \& Harmon-Jones, 2009; Harmon-Jones \& Allen, 1998), and also that positive emotions differing in the extent of approach motivation have differential implications for aspects of cognition and behavior (e.g., Gable \& Harmon-Jones, 2010). Other researchers have considered appraisals of certainty as another dimension along which both positive and negative emotions may vary, with implications for a variety of outcomes (e.g., Tiedens \& Linton, 2001). Both of these dimensionfocused approaches document important variability among positive emotions, showing that only some "do X" as suggested by prior research, whereas others may have quite different effects.

While dimensional approaches have offered one useful and productive approach to investigating the variability among positive emotions, functional analyses of "discrete" emotions offer a complementary approach to this same goal. Rather than developing hypotheses based 
on one dimension of emotional experience at a time, the functional approach starts by asking what kinds of events positive emotions are responses to, and developing hypotheses that reflect bets about what an overall adaptive response to that event might look like (Cosmides \& Tooby, 2000). Our ancestors' environments contained several qualitatively distinct kinds of reliably occurring, fitness-relevant rewards, and different rewards are best approached in somewhat different ways. For example, the fitness-enhancing response to a newborn baby differs considerably from the fitness-enhancing response to a cool drink or a panoramic view. From this perspective, different "discrete" emotions should have evolved to facilitate adaptive responses to these various kinds of situations (Cosmides \& Tooby, 2000; Ekman, 1992; Frijda, 1986; Keltner, Haidt, \& Shiota, 2006; Lazarus, 1991; Nesse, 1990).

Discrete emotions are thought to help address adaptive problems (in this case, opportunities) by coordinating a package of cognitive, physiological, and behavioral mechanisms likely to facilitate a fitness-enhancing response to the situation at hand. In the absence of strong emotion these mechanisms, which include physiological conditions regulated by the autonomic nervous system and hormones, facial muscle movements, tone of voice, posture, and a variety of sensory, attentional, and cognitive processes, operate somewhat independently in response to different aspects of the environment. For example, while walking up a flight of stairs to a professional meeting, one might experience an increase in heart rate, engage executive functions involved in planning, smile politely at a passing colleague, sense mild hunger, and attend to the chirp of nearby birds, all for reasons that are unrelated to each other. Emotions are thought to pull such mechanisms together so that processes supporting a fitness-enhancing response are prioritized, and those that might interfere are suppressed (Levenson, 1999). Cosmides and Tooby (2000) liken this process to a "superordinate computer program" that activates specific sets of "subroutines" including expressive channels, autonomic and hormonal responses, a host of cognitive mechanisms and biases, and algorithms for action. A functional analysis of a particular emotion starts by identifying a frequently occurring kind of situation our ancestors might have encountered, involving either a severe threat to adaptive fitness (negative emotions) or an opportunity to enhance fitness (positive emotions), and then posits a package of subroutines that would have helped them solve that problem.

Functional analyses of negative emotions have guided a great deal of research since the late 1960s, when studies documenting high cross-cultural recognition of several emotional expressions led to increased acknowledgment that emotions could be adaptations (Ekman, 1971; Izard, 1977). The emotions represented in these studies - which were almost exclusively negative became the default set of constructs for both theory and research in the decades that followed. This foundation has supported rich and exciting research on the differing features of fear, anger, sadness, and disgust (e.g., Blair, Morris, Frith, Perrett, \& Dolan, 1999; Cacioppo et al., 2000; Damasio et al., 2000; Keltner, Ellsworth, \& Edwards, 1993; Kreibig, 2010; Lerner \& Keltner, 2001; Levenson, 1992; Phillips et al., 1998; Scherer, 1997; Wheeler, Davidson, \& Tomarken, 1993). Functional analyses were later offered for additional negative constructs such as guilt and embarrassment, further expanding this line of research (e.g., Banse \& Scherer, 1996; Frijda, Kuipers, \& ter Schure, 1989; Keltner \& Buswell, 1997; Smith \& Ellsworth, 1985; Tangney, Miller, Flicker, \& Barlow, 1996). It took much longer for researchers to offer functional analyses for positive emotions, likely because "fitness" was equated with avoiding threats to survival for so long.

\section{Functional Analyses of Positive Emotions: The "PANACEAS" Taxonomy}

By the late 1990s, emotion researchers were acknowledging the importance of fitnessrelevant opportunities as well as threats and updated the meaning of adaptive function in a way that better accounted for positive emotions (e.g., Fredrickson, 1998; Shaver, Morgan, 
\& Wu, 1996; Shiota, Campos, Keltner, \& Hertenstein, 2004; Tracy \& Robins, 2004). Two elements of this update proved especially important. First, researchers recognized that the adaptive functions of positive emotions might involve changes in cognitive processing as well as overt behavior (Fredrickson, 1998). In particular, Fredrickson's broaden-and-build model posits that positive emotions can broaden attention and scope of thought, promoting greater intake of information, more flexible, creative cognition, and downstream expansion of behavioral repertoires (Cunningham, 1988; Fredrickson, 2001; Fredrickson \& Branigan, 2005; Kahn \& Isen, 1993). This point accounts for positive emotion states that appear primarily to facilitate learning, as well as noting the variety of appropriate behavioral responses to potential rewards.

Second, researchers recognized that emotions can be functional not only in the intrapersonal sense - directly promoting the individual's survival and reproductive success - but also in the interpersonal sense, supporting complex and interdependent social relationships (Shaver et al., 1996; Shiota et al., 2004; Tracy \& Robins, 2004). Humans are ultrasocial, unique in the animal kingdom in our dependence on collaborative efforts with large groups of non-kin to fulfill our basic survival needs (hunting, protection from predators, shelter, etc.; Campbell, 1983). Positive emotions and their expression may be the glue that keeps such groups together, eliciting assistance from others (Bower, 1977), signaling commitment to close relationships and evoking commitment in return (Gonzaga, Keltner, Londahl, \& Smith, 2001), promoting prosocial behavior (Schnall, Roper, \& Fessler, 2010), helping us attain, maintain, and communicate social status (Keltner \& Haidt, 2003; Tracy, Shariff, \& Cheng, 2010), and promoting group identification and bonding (e.g., Leary, 2007).

By applying these principles, researchers have offered functional analyses of several positive emotions in the last decade. The PANACEAS taxonomy offers one example of a set of constructs developed in this way. The term "PANACEAS" is based on the first letter of each of the eight emotion constructs in the taxonomy: Pride, Amusement, Nurturant Love, Attachment Love, Contentment, Enthusiasm, Awe, and Sexual Desire. The eight constructs are described below, not in the order suggested by the acronym, but rather in an order that emphasizes grouping in terms of the material, social, and informational types of opportunities addressed by each emotion. The description of each construct includes a functional definition and brief examples of supporting empirical evidence.

Two emotions in the PANACEAS taxonomy are defined primarily as responses to material opportunities, with food as the prototypical reward. Enthusiasm is experienced during anticipation of the reward and serves to motivate appetitive behavior (Griskevicius, Shiota, \& Neufeld, 2010). A rich body of evidence indicates that this state is supported by activity in dopaminergic reward circuits in the brain (O’Doherty, 2004; Panksepp, 1998). Enthusiasm involves attentional narrowing (e.g., Gable \& Harmon-Jones, 2008), increased reliance on previously learned strategies and heuristics (e.g., Griskevicius, Shiota \& Neufeld, 2010), increased sympathetic activation (Shiota, Neufeld, Yeung, Moser, \& Perea, 2011), and willingness to take risks (e.g., Li, Neufeld, Griskevicius, Shiota, \& Kenrick, 2013). In contrast, contentment is experienced after the reward has been consumed. Fredrickson (1998) suggests contentment aids in both physical and mental "digestion". From a physical standpoint, contentment is associated with a profile of increased parasympathetic and reduced sympathetic nervous system activity that inhibits movement and facilitates healthy digestion of food (Kreibig, 2010). With respect to mental digestion, one study found that lab rats engaged in a behavioral satiety routine after eating a food reward showed hippocampal place cell firing in a sequence that was the reverse of the sequence while they had searched for the food in a maze - a pattern thought to consolidate memory for the successful route to reward (Foster \& Wilson, 2006).

Four constructs in the taxonomy reflect important opportunities in the social domain. The term "love", while corresponding to a mid-level or "basic" emotion construct in English 
vocabulary (e.g., Shaver, Schwartz, Kirson, \& O'Connor, 1987), conflates at least three adaptive functions that may be served by different positive emotions (Bowlby, 1969; Shaver et al., 1996). Sexual desire is a response to the opportunity presented by an attractive potential sexual partner, promoting mate acquisition (a.k.a. flirting) and mating behavior. Attachment love, a response to the opportunity presented by committed caregivers, promotes active seeking and/or passive acceptance of nurturance when one is vulnerable and in need. Although the prototypical experience of attachment love is felt by children toward their parents, it is also experienced in close adult relationships. Nurturant love, elicited by physical and behavioral "cuteness" (Lorenz, 1971) and promoting caregiving behavior, reflects the opportunity to provide support and protection to one's kin as well as others with whom one has an interdependent relationship. While there are clear similarities across these types of love with respect to neural and hormonal mechanisms (Feldman, Weller, Zagoory-Sharon, \& Levine, 2007; Panksepp, 1998), studies have also observed important differences in behavioral expression and implications for cognitive processing (e.g., Gonzaga, Turner, Keltner, Campos, \& Altemus, 2006; Griskevicius, Shiota, \& Neufeld, 2010). For example, sexual desire has been found to promote risk-taking, especially among men (Baker \& Maner, 2008; Li, Kenrick, Griskevicius, \& Neuberg, 2012), whereas nurturant love promotes caution and vigilance against risk (Hrdy, 1999; Li et al., 2012).

Like the varieties of love, pride is also adaptive by virtue of its implications in the social domain. In this case, however, the opportunity at stake is that of high status. Pride advertises a socially valued accomplishment, advancing oneself within a hierarchical social structure in order to enhance access to important resources (Tracy \& Robins, 2007; Williams \& DeSteno, 2009). In both lab animals and humans, dominance facilitates behaviors such as reward consumption, risk-taking, and overall behavioral activation (Davis, Krause, Melhorn, Sakai, \& Benoit, 2009; Galinsky, Gruenfeld, \& Magee, 2003). In humans, pride promotes both postural changes (Tracy \& Robins, 2007) and material display behaviors (Griskevicius, Shiota, $\&$ Nowlis, 2010) that draw attention to one's prominence and success.

Two additional positive emotions in the PANACEAS taxonomy reflect opportunities to learn. Amusement is the positive emotion that facilitates and accompanies play, given the opportunity to practice complex skills in a safe environment free of serious consequences (Pellegrini \& Smith, 2005). All mammals play, though play behavior increases with the behavioral complexity of the species, and a similar "play face" expression has been documented in non-human primates, human infants and young children, and human adults (Campos et al., 2013; Dickson, Walker, \& Fogel, 1997; Preuschoft \& van Hooff, 1997; Sarra \& Otta, 2001). Although play can be physical, social, and/or cognitive in nature, all forms of play involve cognitive flexibility and a greater degree of risk-taking than would be observed in the corresponding "real" situation (Pellegrini, Dupuis, \& Smith, 2007). Finally, awe is thought to facilitate the encoding of novel, complex information from the environment that is unaccounted for by one's current understanding of the world (Keltner \& Haidt, 2003; Shiota, Keltner, \& Mossman, 2007). Humans have an apparently unique ability to form schemas, internal representations of the world that we can manipulate cognitively without having to engage in real (and potentially dangerous) trial-and-error (Piaget, 1973). Awe is thought to promote cognitive accommodation, or selective attention to and encoding of schema-discrepant information, allowing us to develop these cognitive resources (e.g., Shiota et al., 2007).

\section{The Functional Approach at Work: Empirical Research}

The point of functional analyses is not to "prove" that a given emotion state is an adaptation, or that it serves a particular function, or even (necessarily) that it is "discrete" in the sense of being categorically distinct. Rather, functional analyses serve to guide empirical research, 
suggesting novel, testable hypotheses about the implications of positive emotion that would not be indicated by more global theories of positive affect, or by dimensional approaches. The three studies described below offer examples of the utility of a functional approach to positive emotion differentiation. While these are just part of a growing body of research, they are especially useful as illustrations because each study compares several positive emotion constructs, rather than just one or two, and because they cover a range of emotional responding across cognitive, physiological, and behavioral effects.

\section{Cognition: implications for persuasive message processing}

A considerable body of research has suggested that individuals in a positive mood process persuasive messages less carefully than those in a neutral or negative mood (e.g., Bless, Bohner, Schwarz, \& Strack, 1990; Bless, Mackie, \& Schwarz, 1992; Mackie \& Worth, 1989). In a typical study, participants are led to feel happy or sad by various means, and then read several strong or several weak arguments for a stance with which most initially disagree (such as the need for comprehensive exams prior to undergraduate graduation). High persuasion by the weak arguments is taken to indicate heuristic-driven processing of the message (e.g., "nine arguments in favor - sounds good to me!"). In a typical study, sad individuals are more persuaded by strong than by weak arguments, consistent with cautious, systematic processing. In contrast, "happy" individuals find the strong and weak arguments to be equally persuasive. A common explanation for this is that positive mood signals a safe, predictable environment, with reduced need for careful scrutiny (Bless et al., 1990).

The functional analyses behind the PANACEAS taxonomy suggest, however, that certain positive emotions may buck this trend. Enthusiasm, contentment, attachment love, and amusement should all increase reliance on tried-and-true heuristics and/or reduce motivation for effortful, systematic processing. However, two positive emotions should have the opposite effect. Nurturant love is thought to facilitate caring for and protecting a vulnerable other. Effective caregiving requires vigilance against potential danger or threat (Hrdy, 1999). Awe is thought to facilitate accommodative, stimulus-driven cognition in order to acquire maximum information from the environment - the opposite of low-effort, heuristic-based processing. In either case, the effect of the emotion should be to increase caution in processing persuasive messages, not to reduce it.

In a study by Vladas Griskevicius and colleagues, these predictions were borne out (Griskevicius, Shiota, \& Neufeld, 2010). In a task like the one described above, participants who had just relived a personal experience evoking awe or nurturant love were more skeptical of a weak but lengthy persuasive message than those in a neutral-affect condition, although these emotions had no effect on persuasion by the strong message (see Figure 1). In contrast, relived experience of enthusiasm, contentment, attachment love, and amusement had the heuristic-enhancing effect observed in prior research. In each condition, ratings of emotional experience used as a manipulation check confirmed that the emotion task had the intended effect. Notably, prior studies had typically elicited positive mood by presenting participants with a funny film clip or by having participants remember a happy memory (which often involves a reunion with loved ones) - tasks that would elicit amusement or attachment love. In a follow-up study, Griskevicius and colleagues (2010) replicated the effects of awe, nurturant love, enthusiasm, and amusement on endorsement of weak persuasive messages and also found that the overall pattern across emotion conditions could not be accounted for by any one dimension such as arousal, certainty, controllability, anticipated effort, or novelty. 


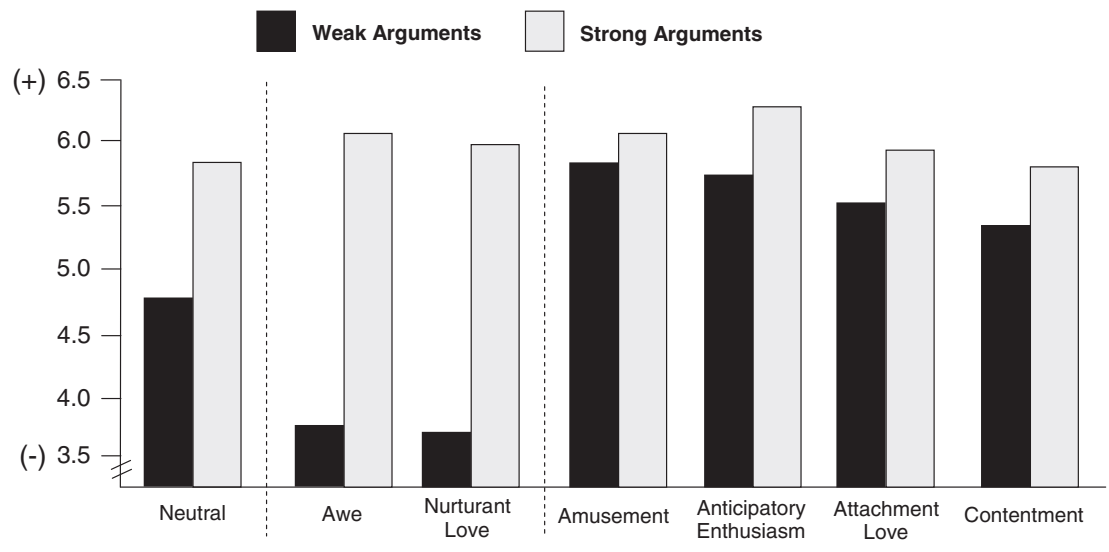

Figure 1. Impact of six positive emotions on persuasion by strong versus weak arguments (reproduced with permission from Griskevicius, Shiota, \& Neufeld, 2010).

Other studies have used functional definitions of one or more positive emotions to predict implications for other aspects of cognition as well. For example, Shiota et al. (2007) found that trait need for cognitive closure is negatively correlated with dispositional awe-proneness, but unrelated to dispositional pride or joy. Oveis, Horberg, and Keltner (2010) found that experimentally elicited pride and compassion led to different patterns of perceived similarity between the self and strong versus weak others. Katzir, Eyal, Meiran, and Kessler (2010) found that, relative to a generic, relived-experience based "happiness" manipulation, a comparable pride manipulation led to increased ability to inhibit visual attention to distractors during a computer-based task. Given the large number of cognitive processes already known to be modulated in some way by emotion, the need for additional research in this area is great.

\section{Physiology: implications for autonomic nervous system responding}

Antonio Damasio (1999, p.51) wrote that "emotions use the body as the theater", and William James (1884) proposed that peripheral physiological reactivity is one of the defining features of emotion. Early studies of the physiological aspects of positive emotion offer conflicting messages. Many studies suggest minimal autonomic involvement in positive emotion, especially in comparison with negative emotions (Cacioppo et al., 2000). Studies of the "undoing effect" also link positive emotion with reduced physiological arousal (e.g., Fredrickson \& Levenson, 1998; Fredrickson et al., 2000). However, other studies have documented increased arousal with amusement and other positive emotions, presumably driven by sympathetic nervous system activation (Kreibig, 2010). Studies often compare the physiological effects of several negative emotions but rarely include more than one or perhaps two positive emotions.

However, one recent study examined the autonomic profiles associated with enthusiasm, attachment love, nurturant love, amusement, and awe (Shiota et al., 2011). Each participant completed several trials; for each trial, physiology was measured during a pre-trial baseline as well as a series of emotion-eliciting slides (emotional effects confirmed through self-ratings of emotion after each trial). Analyses indicated different profiles of baseline-to-slides change in physiology for different emotions, across several measures reflecting different neural mechanisms of "arousal" (Figure 2). For example, enthusiasm, elicited by slides showing a sequence 

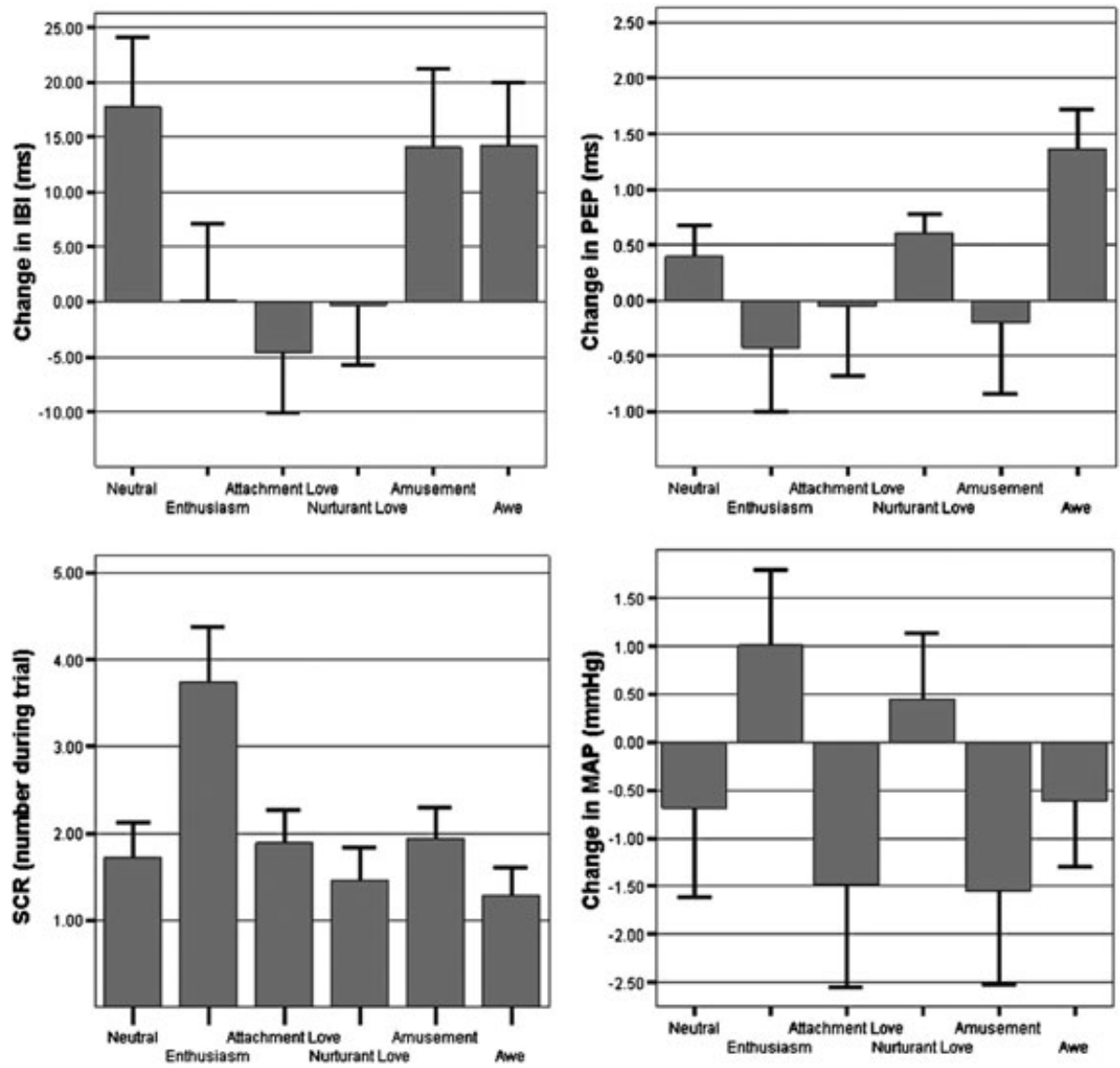

Figure 2. Baseline-to-trial changes in cardiac interbeat interval, pre-ejection period, number of skin conductance response, and mean arterial pressure during five positive emotions (reproduced with permission from Shiota et al., 2011).

of lottery numbers leading to an unexpected monetary reward, evoked a widespread increase in sympathetic nervous system activation across alpha-adrenergic, beta-adrenergic, and cholinergic receptor mechanisms. This response is consistent with the rapid and intense arousal needed to pursue an elusive reward. Attachment love, which was elicited by slides of childhood figures such as Big Bird and Mister Rogers, produced a combination of increased cardiac arousal and reduced blood pressure that suggests an engaged but non-threatened state of activation. Awe, which was elicited by panoramic nature scenes, led to withdrawal of sympathetic nervous system influence on the heart, a response likely to promote intake of information from the environment.

Although more research is needed that compares several positive emotion states within the same study, a growing body of work is documenting the autonomic aspects of positive emotions such as enthusiasm, amusement, contentment, and pride (Kreibig, 2010). Studies have also begun to examine the hormone profiles associated with different positive emotions, finding for example that facial displays of love, but not sexual desire, uniquely predicted increases in circulating levels of oxytocin in women reliving a personal experience of romantic love/infatuation (Gonzaga et al., 2006). It appears that positive emotions, too, use the body as their stage for a variety of performances. 


\section{Motivation and behavior: implications for financial risk-taking}

Like the research on positive emotion physiology, research on implications of positive emotion for risk-taking has been inconsistent. On the one hand, the affective generalization hypothesis holds that positive mood promotes an optimistic assessment of probabilities, and increased willingness to take risks (Johnson \& Tversky, 1983; also Forgas, 1995). On the other hand, the mood-maintenance hypothesis holds that people in a positive mood seek to maintain that mood and thus will tend to avoid risk (Isen \& Patrick, 1983). Jessica Li et al. (2013) asked whether the PANACEAS taxonomy could be used to predict which positive emotions would tend to increase financial risk-taking and which would promote risk-aversion.

$\mathrm{Li}$ and colleagues induced enthusiasm, contentment, nurturant love, amusement, or a neutral-affect state by asking each participant to vividly relive a personal experience likely to elicit the target emotion. The participant was then given 60 one-dollar bills, with which to play a casino-style card game. In this game, although participants were not allowed to keep the money, they were instructed to pretend that they would really get to take their winnings home, and losses would not be recovered; real dollar bills were used to heighten ecological validity. The game was rigged so that all participants faced the same objective level of risk, and the game did not involve skill in any way. Results suggested that enthusiasm and amusement promoted placing higher bets - an approach consistent with emphasis on reward acquisition and willingness to take risks to reap rewards. Bets in the contentment and nurturant love conditions did not differ from those in the neutral condition, consistent with the relative riskaversion likely to result from feelings of satiety and comfort or of caution and responsibility.

Although researchers are just beginning to ask whether different positive emotions have differential implications for motivation and behavior, other early studies also suggest the promise of a functional approach. For example, one set of studies has found that experimentally elicited contentment and pride both promote increased desire for consumer products, but for different kinds of products: contentment enhances desire for products enhancing the comfort of one's home, whereas pride enhances desire for products that can be displayed publicly as "status symbols" (Griskevicius, Shiota, \& Nowlis, 2010). As with cognition and physiology, however, far more research is needed.

\section{Conclusion: The Advantages of a Functional Approach}

As noted earlier, the aim of functional analysis is not to "prove" that emotions are adaptations or that they are categorically discrete. Rather, functional analyses offer a theoretically sound basis for predictions about the differential implications of various emotion states. Functional analyses also aid research by specifying the content of stimuli that should be used to elicit a given state, rather than relying on emotion vocabulary in any particular language. Whether or not emotional responding is consistent with hypotheses then becomes an empirical question; either way, results are useful in advancing theory and guiding future research.

The PANACEAS taxonomy offers one example of how a functional approach to positive emotion differentiation can be applied. The eight constructs in this taxonomy are not necessarily discrete emotions in the sense of being categories with absolute boundaries - in fact, prior research suggests a combination of overlapping and differentiating features. Also, the PANACEAS should not be presumed to completely cover positive emotion space. Subtle variations on each of these constructs may differ in meaningful ways, and it is possible that larger regions of positive emotional experience are unrepresented as well. However, the taxonomy is useful in clearly defining several constructs reflecting material, social, and informational reward domains, all using the same theoretical approach.

The value of research comparing these constructs is not limited to testing the "discrete" or "basic" emotion perspective. Provided that several constructs are included in a study, findings 
can be compared against predictions emerging from dimensional theories emphasizing subjective valence and arousal as the key features of emotional responding (e.g., Russell, 2003; Watson \& Tellegen, 1985), or from the Component Process Model, which emphasizes a dynamic set of stimulus evaluation checks (e.g., goal conduciveness, certainty, and control) as the mechanism that produces emotional responding (Scherer, 2009). Indeed, many studies used to support the Component Process Model compare the features of negative emotion constructs defined previously via functional analyses (e.g., Banse \& Scherer, 1996; Scherer, 1997). The utility of the functional approach lies in facilitating comparison across wide reaches of positive emotion space, with clear theoretical definitions of each point in space that is being studied.

Although it may seem counterintuitive, a functional approach to positive emotion differentiation also serves another useful purpose - discouraging the assumption that all effects of positive emotion are positive. The distinction between "functional" and "desirable" is important in this regard. Functionality, in the evolutionary sense, is context-specific. Moreover, the context in question (the "Environment of Evolutionary Adaptedness", or set of selection pressures in the ancestral environment that led to an adaptation) is not modern industrial society, so our "adaptive" emotional response systems may have quite undesirable side effects here and now. Consider alcohol and drug addiction, obesity, compulsive gambling, uncontrolled spending, relationship-damaging sexual behavior, and status-related abuse of power. Although researchers have long noted that the cognitive effects of positive emotion are not always desirable (e.g., Bless et al., 1990; Bless et al., 1992; Mackie \& Worth, 1989), recent analyses note that excessive experience or pursuit of positive emotions can also have harmful implications for mental health and well-being (e.g., Gruber, Johnson, Oveis, \& Keltner, 2008; Gruber, Mauss, \& Tamir, 2011; Mauss, Tamir, Anderson, \& Savino, 2011). A functional approach supports hypotheses about a wide variety of emotion response processes that should have been adaptive, on average, in our ancestral environment, but which may be less desirable in the modern world.

At the same time, a functional approach to positive emotion differentiation can help balance the growing body of research on human nature. Evolutionary psychology has often sought to explain the worst of human feeling and action in terms of adaptive function. While this approach highlights a distinct contribution that evolutionary psychology can offer, it can send the impression that human nature only consists of our worst qualities. Fortunately, researchers are beginning to articulate the "better angels of our nature" in evolutionary terms as well (De Waal, 2009; Keltner, 2009; Pinker, 2011). While positive emotions may not have unreservedly positive effects, they are still mechanisms that help promote a rich, fulfilling, connected, and compassionate life.

\section{Acknowledgement}

The authors wish to express their gratitude to several collaborators whose work is reflected in this manuscript, including Vladas Griskevicius, Jessica Li, Doug Kenrick, Stephanie Moser, Ellen Yeung, and Elaine Perea. Co-authors Osborne, Sng, and Yee were supported in part by a grant to the first author from the John Templeton Foundation during the preparation of this manuscript. The opinions expressed in this manuscript are those of the authors and do not necessarily reflect the views of the John Templeton Foundation.

\section{Short Biographies}

Michelle "Lani" Shiota received her undergraduate degree from Stanford University and her doctorate in Psychology from UC Berkeley. She is now an Associate Professor of Psychology at Arizona State University. Her research on positive emotions, positive reappraisal as an 
emotion regulation strategy, and aging and emotion has been published in Journal of Personality and Social Psychology, Emotion, Social, Cognitive, and Affective Neuroscience, Psychology and Aging, Journal of Consumer Research, Cognition and Emotion, and the Journal of Positive Psychology. She is author, alongside Jim Kalat, of the textbook Emotion (Wadsworth-Cengage Learning), and co-editor of the forthcoming Handbook of Positive Emotions (Guilford). She is also an Associate Editor of the APA journal Emotion. Her most recent research addresses cognitive implications of the emotion awe, as well as the nature and effects of emotion in close relationships.

Samantha Neufeld completed her BA at UC Berkeley and received her PhD in Psychology from ASU in 2012. She is now a Design Researcher at Microsoft. Her research has examined behavioral outcomes associated with guilt as well as implications of emotions for conservation behavior.

Alexander F. Danvers is enrolled in ASU's Social Psychology Doctoral Program. Alex Danvers completed his undergraduate work at the College of William and Mary, and his research addresses the role of positive emotions in the early stages of affiliative social interaction.

Elizabeth A. Osborne is enrolled in ASU's Social Psychology Doctoral Program. Beth Osborne completed her undergraduate work at Florida State University, and her research investigates emotional and motivational mechanisms of social cognition, disease avoidance, and mate choice.

Oliver Sng is enrolled in ASU's Social Psychology Doctoral Program. Oliver Sng completed his undergraduate work at the National University of Singapore, and his research focuses on evolutionary psychology approaches to interpersonal attraction and stereotyping.

Claire I. Yee is enrolled in ASU's Social Psychology Doctoral Program. Claire Yee completed her bachelor's degree at ASU, and her research examines emotional mechanisms of close relationships.

Note

* Correspondence: Department of Psychology, Arizona State University, Tempe, AZ, USA. Email: Lani.Shiota@asu.edu

\section{References}

Baker, M. D., \& Maner, J. K. (2008). Risk-taking as a situationally sensitive male mating strategy. Evolution and Human Behavior, 29, 391-395.

Banse, R., \& Scherer, K. R. (1996). Acoustic profiles in vocal emotion expression. Journal of Personality and Social Psycholog, , 70, 614-636.

Blair, R. J. R., Morris, J. S., Frith, C. D., Perrett, D. I., \& Dolan, R. J. (1999). Dissocial neural responses to facial expressions of sadness and anger. Brain, 122, 883-893.

Bless, H., Bohner, G., Schwarz, N., \& Strack, F. (1990). Mood and persuasion: A cognitive response analysis. Personality and Social Psychology Bulletin, 16, 331-345.

Bless, H., Mackie, D. M., \& Schwarz, N. (1992). Mood effects on attitude judgments: Independent effects of mood before and after message elaboration. Journal of Personality and Social Psychology, 63, 585-595.

Bodenhausen, G. V., Kramer, G. P., \& Süsser, K. (1994). Happiness and stereotypic thinking in social judgment. Journal of Personality and Social Psychology, 66, 621-632.

Bower, T. G. (1977). A Primer of Infant Development. San Francisco: Freeman.

Bowlby, J. (1969). Attachment. Attachment and Loss (Vol. 1). New York: Basic Books.

Cacioppo, J. T., Berntson, G. G., Larsen, J. T., Poehlmann, K. M., \& Ito, T. A. (2000). The psychophysiology of emotion. In M. Lewis \& J. M. Haviland-Jones (Eds.), Handbook of Emotions, 2nd Edition (pp. 173-191). New York: Guilford.

Campbell, D. T. (1983). The two distinct routes beyond kin selection to ultrasociality: Implications for the humanities and social sciences. In D. Bridgeman (Ed.), The Nature of Prosocial Development: Theories and Strategies (pp. 11-39). New York: Academic Press. 
Campos, B., Shiota, M. N., Keltner, D., Gonzaga, G. C., Goetz, J., \& Shin, M. (2013). What is shared, what is different?: Core relational themes and expressive displays of eight positive emotions. Cognition and Emotion, 27, 37-52.

Carver, C. S., \& Harmon-Jones, E. (2009). Anger is an approach-related affect: Evidence and implications. Psychological Bulletin, 135, 183-204.

Carver, C. S., \& White, T. L. (1994). Behavioral inhibition, behavioral activation, and affective responses to impending reward and punishment: The BIS/BAS scales. Journal of Personality and Social Psychology, 67, 319-333.

Cosmides, L., \& Tooby, J. (2000). Evolutionary psychology and the emotions. In Lewis, M. \& Haviland-Jones, J. M. (Eds.), Handbook of Emotions 2nd Edition (pp. 91-115). New York: Guilford.

Cunningham, M. R. (1988). What to do when you're happy or blue? Mood, expectancies, and behavioral interest. Motivation and Emotion, 12, 309-331.

Damasio, A. (1999). The Feeling of What Happens: Body and Emotion in the Making of Consciousness. Fort Worth, TX: Harcourt College.

Damasio, A. R., Grabowski, T. J., Bechara, A., Damasio, H., Ponto, L. L. B., Parvizi, J., Hichwa, R. D. (2000). Subcortical and cortical brain activity during the feeling of self-generated emotions. Nature Neuroscience, 3, 1049-1057.

Davis, J. F., Krause, E. G., Melhorn, S. J., Sakai, R. R., \& Benoit, S. C. (2009). Dominant rats are natural risk takers and display increased motivation for food reward. Neuroscience, 162, 23-30.

De Waal, F. (2009). The Age of Empathy: Nature's Lessons for a Kinder Society. New York, NY: Harmony Books.

Dickson, K. L., Walker, H., \& Fogel, A. (1997). The relationship between smile type and play type during parent-infant play. Developmental Psychology, 33, 925-933.

Diener, E. (2000). Subjective well-being: The science of happiness and a proposal for a national index. American Psychologist, 55, 34-43.

Ekman, P. (1971). Universals and cultural differences in facial expressions of emotion. In J. Cole (Ed.), Nebraska Symposium on Motivation, 1971, Vol. 19 (pp. 207-183). Lincoln, NE: University of Nebraska Press.

Ekman, P. (1992). An argument for basic emotions. Cognition and Emotion, 6, 169-200.

Ekman, P., Friesen, W. V., O’Sullivan, M., Chan, A., Diacoyanni-Tarlatzis, I., Heider, K., et al. (1987). Universals and cultural differences in the judgments of facial expressions of emotion. Journal of Personality and Social Psychology, 51, 712-717.

Feldman, R., Weller, A., Zagoory-Sharon, O., \& Levine, A. (2007). Evidence for a neuroendocrinological foundation of human affiliation: Plasma oxytocin levels across pregnancy and the postpartum period predict mother-infant bonding. Psychological Science, 18, 965-970.

Forgas, J. P. (1995). Mood and judgment: The affect infusion model. Psychological Bulletin, 117, 39-66.

Forgas, J. P. (2008). Affect and cognition. Perspectives on Psychological Science, 3, 94-101.

Foster, D. J., \& Wilson, M. A. (2006). Reverse replay of behavioural sequences in hippocampal place cells during the awake state. Nature, 440, 680-683.

Fredrickson, B. L. (1998). What good are positive emotions? Review of General Psychology, 2, 300-319.

Fredrickson, B. L. (2001). The role of positive emotions in positive psychology: The broaden-and-build theory of positive emotions. American Psychologist, 56, 218-226.

Fredrickson, B. L., \& Branigan, C. (2005). Positive emotions broaden the scope of attention and build thought-action repertoires. Cognition and Emotion, 19, 313-332.

Fredrickson, B. L., \& Joiner, T. (2002). Positive emotions trigger upward spirals toward emotional well-being. Psychological Science, 13, 172-175.

Fredrickson, B. L., \& Levenson, R. W. (1998). Positive emotions speed recovery from the cardiovascular sequelae of negative emotions. Cognition \& Emotion, 12, 191-220.

Fredrickson, B. L., Mancuso, R. A., Branigan, C., \& Tugade, M. M. (2000). The undoing effect of positive emotions. Motivation and Emotion, 24, 237-258.

Frijda, N. H. (1986). The Emotions. Cambridge: Cambridge University Press.

Frijda, N. H., Kuipers, P., \& ter Schure, E. (1989). Relations among emotion, appraisal, and emotional action readiness. Journal of Personality and Social Psychology, 57, 212-228.

Gable, P. S., \& Harmon-Jones, E. (2008). Approach-motivated positive affect reduces breadth of attention. Psychological Science, 19, 476-482.

Gable, P., \& Harmon-Jones, E. (2010). The motivational dimensional model of affect: Implications for breadth of attention, memory, and cognitive categorisation. Cognition and Emotion, 24, 322-337.

Galinsky, A. D., Gruenfeld, D. H., \& Magee, J. C. (2003). From power to action. Journal of Personality and Social Psychology, 85, 453-466.

Gonzaga, G. C., Keltner, D., Londahl, E. A., \& Smith, M. (2001). Love and the commitment problem in romantic relations and friendship. Journal of Personality and Social Psychology, 81, 247-262.

Gonzaga, G. C., Turner, R. A., Keltner, D., Campos, B., \& Altemus, M. (2006). Romantic love and sexual desire in close relationships. Emotion, 6, 163-179. 
Griskevicius, V., Shiota, M. N., \& Neufeld, S. L. (2010). Influence of different positive emotions on persuasion processing: A functional evolutionary approach. Emotion, 10, 190-206.

Griskevicius, V., Shiota, M. N., \& Nowlis, S. M. (2010). The many shades of rose-colored glasses: Discrete positive emotions and product perception. Journal of Consumer Research, 37, 238-250.

Gruber, J., Johnson, S. L., Oveis, C., \& Keltner, D. (2008). Risk for mania and positive emotional responding: Too much of a good thing? Emotion, 8, 23-33.

Gruber, J., Mauss, I. B., \& Tamir, M. (2011). A dark side of happiness? How, when, and why happiness is not always good. Perspectives on Psychological Science, 6, 222-233.

Harker, L. A., \& Keltner, D. (2001). Expressions of positive emotion in women's college yearbook pictures and their relationship to personality and life outcomes across adulthood. Journal of Personality and Social Psychology, 80, $112-124$.

Harmon-Jones, E. (2003). Clarifying the emotive functions of asymmetrical frontal cortical activity. Psychophysiology, 40, 838-848.

Harmon-Jones, E., \& Allen, J. J. B. (1998). Anger and frontal brain activity: EEG asymmetry consistent with approach motivation despite negative valence. Journal of Personality and Social Psychology, 74, 1310-1316.

Hrdy, S. B. (1999). Mother Nature: Maternal Instincts and How They Shape the Human Species. New York: Pantheon.

Huntsinger, J. R., Sinclair, S., Dunn, E., \& Clore, G. L. (2010). Affective regulation of stereotype activation: It's the (accessible) thought that counts. Personality and Social Psychology Bulletin, 36, 564-577.

Isen, A. M., \& Patrick, R. (1983). The effect of positive feelings on risk taking: When the chips are down. Organizational Behavior and Human Performance, 31, 194-202.

Isen, A. M., Daubman, K. A., \& Nowicki, G. P. (1987). Positive affect facilitates creative problem solving. Journal of Personality and Social Psychology, 52, 1122-1131.

Izard, C. E. (1977). Human Emotions. New York: Plenum Press.

James, W. (1884). What is an emotion? Mind, 9, 188-205.

Johnson, K. J., \& Fredrickson, B. L. (2005). "We all look the same to me": Positive emotions eliminate the own-race bias in face recognition. Psychological Science, 16, 875-881.

Johnson, E. J., \& Tversky, A. (1983). Affect, generalization, and the perception of risk. Journal of Personality and Social Psychology, 45, 20-31.

Kahn, B. E., \& Isen, A. M. (1993). The influence of positive affect on variety seeking among safe, enjoyable products. Journal of Consumer Research, 20, 257-270.

Katzir, M., Eyal, T., Meiran, N., \& Kessler, Y. (2010). Imagined positive emotions and inhibitory control: The differentiated effect of pride versus happiness. Journal of Experimental Psychology: Learning, Memory, and Cognition, 36, 1314.

Keltner, D. (2009). Born To Be Good: The Science of a Meaningful Life. New York: W. W. Norton.

Keltner, D., \& Buswell, B. N. (1997). Embarrassment: Its distinct form and appeasement functions. Psychological Bulletin, 122, 250-270.

Keltner, D., \& Haidt, J. (2003). Approaching awe: A moral, spiritual, and aesthetic emotion. Cognition and Emotion, 17, $297-314$.

Keltner, D., Ellsworth, P. C., \& Edwards, K. (1993). Beyond simple pessimism: Effects of sadness and anger on social perception. Journal of Personality and Social Psychology, 64, 740-752.

Keltner, D., Haidt, J., \& Shiota, M. N. (2006). Social functionalism and the evolution of emotions. In M. Schaller, J. A. Simpson \& D. T. Kenrick (Eds.), Evolution and Social Psychology (pp. 115-142). New York: Psychology Press.

Kreibig, S. D. (2010). Autonomic nervous system activity in emotion: A review. Biological Psychology, 84, $394-421$.

Lazarus, R. S. (1991). Emotion and Adaptation. New York: Oxford University Press.

Leary, M. R. (2007). Motivational and emotional aspects of the self. Annual Review of Psychology, 58, $317-344$.

Lerner, J. S., \& Keltner, D. (2001). Fear, anger, and risk. Journal of Personality and Social Psychology, 81, 146-159.

Levenson, R. W. (1992). Empathy: A physiological substrate. Journal of Personality and Social Psychology, 63, $234-246$.

Levenson, R. W. (1999). The intrapersonal functions of emotion. Cognition E Emotion, 13, 481-504. Nesse, R. M., \& Ellworth, P. C. (2009). Evolution, emotions, and emotional disorders. American Psychologist, 64, 129-139.

Li, Y. J., Kenrick, D. T., Griskevicius, V., \& Neuberg, S. L. (2012). Economic decision biases and fundamental motivations: How mating and self-protection alter loss aversion. Journal of Personality and Social Psychology, 102, 550-561.

Li, Y. J., Neufeld, S. L., Griskevicius, V., Shiota, M. N., \& Kenrick, D. T. (2013). A positive spin on risk-taking: Discrete positive emotions affect financial decisions. Manuscript in preparation.

Lorenz, K. (1971). Studies in Animal and Human Behaviour, Vol. 2. (R. Martin, Trans.). Cambridge, MA: Harvard University Press.

Mackie, D. M., \& Worth, L. T. (1989). Processing deficits and the mediation of positive affect in persuasion. Journal of Personality and Social Psychology, 57, 27-40.

Mauss, I. B., Tamir, M., Anderson, C. L., \& Savino, N. S. (2011). Can seeking happiness make people unhappy? Paradoxical effects of valuing happiness. Emotion, 11, 807-815.

Nesse, R. M. (1990). Evolutionary explanations of emotions. Human Nature, 1, 261-289.

Nesse, R. M., \& Ellsworth, P. C. (2009). Evolution, emotions, and emotional disorders. American Psychologist, 64, 129-139. 
O’Doherty, J. P. (2004). Reward representations and reward-related learning in the human brain: Insights from neuroimaging. Current Opinion in Neurobiology, 14(6), 769-776.

Oveis, C., Horberg, E. J., \& Keltner, D. (2010). Compassion, pride, and social intuitions of self-other similarity. Journal of Personality and Social Psychology, 98, 618.

Panksepp, J. (1998). Affective Neuroscience: The Foundations of Human and Animal Emotions. New York: Oxford.

Pellegrini, A. D., \& Smith, P. K. (2005). The Nature of Play: Great Apes and Humans. New York, NY: Guilford.

Pellegrini, A. D., Dupuis, D., \& Smith, P. K. (2007). Play in evolution and development. Developmental Review, 27, $261-276$.

Phillips, M. L., Young, A. W., Scott, S. K., Calder, A. J., Giampietro, C. A. V., Williams, S. C. R., Bullmore, E. T., Brammer, M., \& Gray, J. A. (1998). Neural responses to facial and vocal expressions of fear and disgust. Proceedings of the Royal Society of London B, 265, 1809-1817.

Piaget, J. (1973). The Child and Reality: Problems of Genetic Psychology. Oxford, England: Grossman.

Pinker, S. (2011). The Better Angels of Our Nature. New York: Viking.

Pressman, S. D., \& Cohen, S. (2005). Does positive affect influence health? Psychological Bulletin, 131, 925-971.

Preuschoft, S., \& van Hooff, J. A. R. A. M. (1997). The social function of "smile" and "laughter": Variations across primate species and societies. In U. Segerstrale \& P. Molnar (Eds.), Nonverbal Communication: Where Nature Meets Culture. Mahwah, NJ: Lawrence Erlbaum.

Russell, J. A. (2003). Core affect and the psychological construction of emotion. Psychological Review, 110, $145-172$.

Sarra, S., \& Otta, E. (2001). Different types of smiles and laughter in preschool children. Psychological Reports, 89, 547-558.

Scherer, K. R. (1997). The role of culture in emotion-antecedent appraisal. Journal of Personality and Social Psychology, 73, 902-922.

Scherer, K. R. (2009). The dynamic architecture of emotion: Evidence for the component process model. Cognition and Emotion, 23, 1307-1351.

Schnall, S., Roper, J. \& Fessler, D. M. T. (2010). Elevation leads to altruistic behavior. Psychological Science, 21, 315-320.

Shaver, P. R., Morgan, H. J., \& Wu, S. (1996). Is "love” a basic emotion? Personal Relationships, 3, 81-96.

Shaver, P., Schwartz, J., Kirson, D., \& O’Connor, C. (1987). Emotion knowledge: Further exploration of a prototype approach. Journal of Personality and Social Psychology, 52, 1061-1086.

Shiota, M. N., Campos, B., Keltner, D., \& Hertenstein, M. J. (2004). Positive emotion and the regulation of interpersonal relationships. In P. Philippot \& R. S. Feldman (Eds.), The Regulation of Emotion (pp. 127-155). Mahwah, N.J.: Lawrence Erlbaum.

Shiota, M. N., Keltner, D., \& Mossman, A. (2007). The nature of awe: Elicitors, appraisals, and effects on self-concept. Cognition and Emotion, 21, 944-963.

Shiota, M. N., Neufeld, S. L., Yeung, W. H., Moser, S. E., \& Perea, E. F. (2011). Feeling good: Autonomic nervous system responding in five positive emotions. Emotion, 11, 1368-1378.

Smith, C. A., \& Ellsworth, P. C. (1985). Patterns of cognitive appraisal in emotion. Journal of Personality and Social Psychology, 48, 813-838.

Steptoe, A., Wardle, J., \& Marmot, M. (2005). Positive affect and health-related neuroendocrine, cardiovascular, and inflammatory processes. Proceedings of the National Academy of Sciences, 102, 6508-6512.

Tangney, J. P., Miller, R. S., Flicker, L., \& Barlow, D. H. (1996). Are shame, guilt, and embarrassment distinct emotions? Journal of Personality and Social Psychology, 70, 1256-1269.

Tiedens, L. Z., \& Linton, S. (2001). Judgment under emotional certainty and uncertainty: The effects of specific emotions on information processing. Journal of Personality and Social Psychology, 81, 973.

Tracy, J. L., \& Robins, R. W. (2004). Show your pride: Evidence for a discrete emotion expression. Psychological Science, 15, 194-197.

Tracy, J. L., \& Robins, R. W. (2007). The prototypical pride expression: Development of a nonverbal behavior coding system. Emotion, 7, 789-801.

Tracy, J. L., Shariff, A. F., \& Cheng, J. T. (2010). A naturalist's view of pride. Emotion Review, 2, $163-177$.

Tugade, M. M., Fredrickson, B. L., \& Feldman Barrett, L. (2004). Psychological resilience and positive emotional granularity: Examining the benefits of positive emotions on coping and health. Journal of Personality, 72, 1161-1190.

Watson, D., \& Tellegen, A. (1985). Toward a consensual structure of mood. Psychological Bulletin, 98, $219-235$.

Wheeler, R. E., Davidson, R. J., \& Tomarken, A. J. (1993). Frontal brain symmetry and emotional reactivity: A biological substrate of affective style. Psychophysiology, 30, 82-89.

Williams, L. A., \& DeSteno, D. (2009). Pride: Adaptive social emotion or seventh sin? Psychological Science, 20, $284-288$. 